\title{
Participation's Motives in Dancing Activities. Gender and Age as Differentiation Factors
}

Doi:10.5901/mjss.2015.v6n3s1p535

\author{
1Stavridis, A. \\ ${ }^{2}$ Kaprinis, St. \\ ${ }^{3}$ Tsirogiannis, I. \\ 114th Elementary School of Veria, \\ 2 Department of Sport Management, University of Peloponnese \\ ${ }^{3}$ Department of Physical Education and Sports Sciences of Serres, Aristotle University
}

\section{Abstract}

Dancing, in every form, is defined as a physical activity that according to researchers is suitable for both sexes, for every age, for people with different education level and different professional careers. The aim of this research was to investigate what motivates the people who take part in dancing activities and especially in performance dancing. A secondary aim was to investigate group differences across gender and age. The sample of the investigation was 220 dancers of groups of performance dancing, where Greek folk dance is taught, and of private dance schools where ballet, Latin, contemporary dance and other kinds are taught. The Greek version (Foridou, Tsitskari, Bebetsos, Vernadakis, 2012) of Behaviour Regulation in Sport Questionnaire (Lonsdale, Hodge, Rose, 2008) was used for the data collection. Cronbach's alphas were calculated to check the internal consistencies of the subscales of the measurements. Comparisons in dancers' motives were examined across gender and age. An independent -samples t-test was used to investigate the group differences across gender and Oneway analysis of variance was used to examine the group differences across age. The analysis of the results indicates that: a) the factors "Intrinsic Motivation - General", "Intrinsic Motivation to Experience Stimulation" and "Intrinsic Motivation to Know" are more important for the sample, b) sex is not a factor that differentiates the motives of participation, and c) younger dancers are more inclined to dance than older dancers. In conclusion, we can assume that dancing is a suitable activity for everyone, and gives the pleasure and satisfaction to the participants without aiming to specific benefits.

Keywords: traditional, classic and contemporary dance, motivation

\section{Introduction}

It is widely acknowledged that participation in physical activities can affect positively one's health (WHO, 2010). However, this perspective is not entirely true, as a variety of researches have proved (Thesleff, 2014). More specifically, longtime participation in competitive activities, such as sports and professional dance might result in ill- instead of well-being (Bartholomew, Ntoumanis \& Thøgersen-Ntoumani, 2009).

Dancing, in every form, is defined as a physical activity that according to researchers is suitable for both sexes, for every age, for people with different education level and different professional careers. Dancing is an activity that leads to a comprehensive engagement of the participants. It contributes to the improvement of all physical abilities related to health (Mavridis, Filippou, Rokka, Bousiou \& Mavridis, 2004), is a recreational activity, a mean of socialization and knowledge of the culture of people (Filippou et al., 2006) but also a mean of personal expression (Filippou, 2014; Pitsi, Filippou, 2014).

\section{Literature Review}

Many researchers have been occupied with the investigation of the motives of those who participate in classes where folk dances are taught. Thus, according to Zanou, Chasandra, and Goudas (2001), adults take part in Greek folk dancing groups because of the satisfying atmosphere and the positive spirit of the classes. Similar are the results of the research that was conducted by Doulias, Kosmidou, Pavlogiannis and Patsiaouras (2005) the results indicate that the motives of the adolescents for the participation in folk dancing groups were fun, the need to belong to a group as well as the need to make friends. On the contrary, success and prestige were not included in their motives.

A research conducted by McCleary, Weaver and Meng (2006) revealed six factors that motivate Americans to participate in dancing activities (lessons of social dances and dance festivals). These factors are: "escape and relaxation", "sociability", "originality", "learning dances-improvement of dancing skills", "satisfaction" and "enthusiasm", 
with the factor "escape and relaxation" being the most important for the participants at 15,1\%.

In a different research, conducted by Baxevanos (2008), 454 adults, members of dancing groups, were the sample. Its results showed that the sample saw dancing as a physical activity and as a result as a way of enhancing health; also another motive of participation in classes was to improve dancing knowledge and dancing skills.

The common element among all these researches is that the motives that are examined are those of amateur dancers and especially of dancers of folk dances. The only research that examined the motives of dance students in the one conducted by Thesleff (2014). Its results indicated that dance students are mainly intrinsically motivated, as the extrinsic motivation was not a popular option.

In Greece there are circa 2000 active dance groups where Greek folk dancing is taught. The most substantial moment is their annual performances that are occur mainly in summer. Furthermore, 600 dancing schools where all kinds of dancing are taught to amateurs, as well as to professionals. The review of the bibliography indicates that there are no researches conducted concerning the participation motives of dancers in dancing groups that are occupied with performance dancing. Knowing the reasons that influence somebody to participate in grouped physical activities, such as organized dance lessons, will enable not only dance instructors but also coordinators of dancing groups to organize their classes, based on this specific knowledge. As a result of this process, the participants will be satisfied from the classes and will keep participating in their dancing groups. The importance of this is indisputable as experienced dancers constitute the foundation of the dancing groups and more specifically of the performances that occur throughout the year.

Thus, the aim of this research is to investigate the participation motives of dancers who take part in groups where their aim is performance dancing. A secondary aim was to investigate group differences across gender and age.

\section{Methodology}

\subsection{Sample}

The sample of the investigation was 220 dancers of groups of performance dancing, where Greek folk dance is taught, and of private dance schools where ballet, Latin, contemporary dance and other kinds are taught. The demographic characteristics of the sample are shown in Table 1.

The sample, that was consisted of dancers who were interested in different kinds of dancing was a conscious choice, since the aim of this research was the investigation of the motives of participation of people who do take part in performance dancing and not only see it as a leisure activity. It is the first time in Greece that a research like this is conducted, as all the previous ones have examined solely the motives of participation in classes where Greek folk dancing was seen only as a leisure activity; what is more the previous researches were not concerned further with different kinds of dancing whatsoever.

Table 1. Demographic characteristics of the sample

\begin{tabular}{|c|c|c|c|c|}
\hline \multirow{2}{*}{$\begin{array}{l}\text { Dance Form \& Gender (\%) } \\
\text { Traditional / Non traditional }\end{array}$} & \multicolumn{2}{|c|}{ Age } & \multicolumn{2}{|c|}{ Educational level } \\
\hline & & & & \\
\hline Male/Female Male/Female & Group & $(\%)$ & & $\%$ \\
\hline \multirow[t]{6}{*}{$\begin{array}{ll}19.0 / 32.3 & 5.91 / 42.73\end{array}$} & $15-18$ & 48.6 & Primary school & 1.4 \\
\hline & $19-29$ & 19.6 & Secondary school & 67.7 \\
\hline & $30-39$ & 12.7 & Technical school & 8.2 \\
\hline & $40-49$ & 9.6 & University & 22.7 \\
\hline & $50-59$ & 5.0 & & \\
\hline & $60+$ & 4.5 & & \\
\hline
\end{tabular}

\subsection{Data collection}

The Greek version (Foridou, Tsitskari, Bebetsos, Vernadakis, 2012) of Behaviour Regulation in Sport Questionnaire (BRSQ) (Lonsdale, Hodge and Rose, 2008) was used for the data collection. The form of this specific questionnaire is used for the first time in a research for dancing in Greece, as the previous one, which was conducted by Foridou, Tsitskari, Bebetsos and Vernadakis (2012) was concerned about children's motives of participation in sport activities. Furthermore, the questionnaire was used successfully in a similar research conducted by Thesleff (2014) in Finland.

The participants answered a stem question "I participate in dancing activity...", and the scale consists of 9 subscales: a. Intrinsic Motivation - General (e.g. because I enjoy it), b. Intrinsic Motivation to Know (e.g. because I enjoy learning new techniques, c. Intrinsic Motivation to Experience Stimulation (e.g. because of the excitement I feel when I 
am really involved in the activity, d. Intrinsic Motivation to Accomplish (e.g. because I enjoy the feeling of achievement when trying to reach long-term goals, e. Integrated Regulation (e.g. because it's a part of who I am), f. Identified Regulation (e.g. because the benefits of dance are important to me), g. Introjected Regulation (e.g. because I would feel ashamed if I quit), h) External Regulation (e.g. because if I don't other people will not be pleased with me) and $\mathrm{j}$. Amotivation (e.g. but I wonder what the point is). Each item uses a 7-point Likert scale ranging from $1=$ not at all true to 7 = very true.

\subsection{Measurement Process}

The participants gave their consent for their attendance in the study. The completion of questionnaire was anonymous and it was carried out in the practice grounds before or after dancing lesson. The completion time was around 15 minutes. After filling in their questionnaires, they placed them in a poll in order to secure their anonymity.

\section{Data Analyses}

Cronbach's alphas were calculated to check the internal consistencies of the subscales of the measurements. Comparisons in dancers' motives were examined across gender and age. An independent -samples t-test was used to investigate the group differences across gender and One-way analysis of variance (ANOVA) was used to examine the group differences across age.

\section{Results}

The reliability of the subscales was examined by calculating the Cronbach's alpha coefficient. The analysis showed that the factors have a satisfactory reliability degree (a>.60) (Table 2).

Table 2. Reliability analysis, Means and Standard Deviation of the nine factors.

\begin{tabular}{|l|c|c|c|c|}
\hline Factors & $\mathbf{N}$ & Mean & S.D. & Cronbach's a \\
\hline Intrinsic Motivation - General & 220 & 6.03 & .64 & .83 \\
\hline Intrinsic Motivation to Experience Stimulation & 220 & 5.33 & .75 & .88 \\
\hline Intrinsic Motivation to Know & 220 & 5.25 & .97 & .93 \\
\hline Intrinsic Motivation to Accomplish & 220 & 4.89 & 1.12 & .94 \\
\hline Identified Regulation & 220 & 4.53 & .74 & .76 \\
\hline Integrated Regulation & 220 & 4.28 & 1.10 & .94 \\
\hline Introjected Regulation & 220 & 2.54 & .80 & .90 \\
\hline External Regulation & 220 & 1.70 & .48 & .76 \\
\hline Amotivation & 220 & 1.43 & .40 & .63 \\
\hline
\end{tabular}

\section{Gender as Differentiation Factor}

To check whether there were statistically important differences towards the twelve factors, owed to participants' gender, nine T-tests for independent samples were performed. From the results it is evident that gender does not constitute a differential factor.

\section{Age as Differentiation Factor}

One-way analysis of variance was conducted to indicate any differences in class attendance of the sample. Results revealed significant statistical differences on the subscales of:

1. "Intrinsic Motivation to Know" $f_{(5,214)}=43,17, p<.05$. More specifically: a. Male and female dancers of $15-18$ age had a higher score $(M=5.59, S D=.62)$ than male and female dancers of $40-49(M=4.08, S D=.80), 50-59$ $(\mathrm{M}=3.77, \mathrm{SD}=.52)$ and 60 plus $(\mathrm{M}=3.45, \mathrm{SD}=.16)$. b. Male and female dancers of $19-29$ age had a higher score $(M=5.67, S D=.63)$ than male and female dancers of $40-49(M=4.08, S D=.80), 50-59(M=3.77, S D=.52)$ and 60 plus $(\mathrm{M}=3.45, \mathrm{SD}=.16)$. c. Male and female dancers of $30-39$ age had a higher score $(\mathrm{M}=5.32$, $\mathrm{SD}=1.06)$ than male and female dancers of $40-49(\mathrm{M}=4.08, \mathrm{SD}=.80), 50-59(\mathrm{M}=3.77, \mathrm{SD}=.52)$ and 60 plus $(\mathrm{M}=3.45, \mathrm{SD}=.16)$. 
2. "Intrinsic Motivation to accomplish $\mathrm{f}_{(5,214)}=124,85, \mathrm{p}<.05$. More specifically: a. Male and female dancers of 15 18 age had a higher score $(M=5.46, S D=.59)$ than male and female dancers of 30-39 ( $M=4.76, S D=.44), 40-49$ $(\mathrm{M}=3.29, \mathrm{SD}=.50), 50-59(\mathrm{M}=2.73, \mathrm{SD}=.34)$ and 60 plus $(\mathrm{M}=2.58, \mathrm{SD}=.55)$. b. Male and female dancers of 1929 age had a higher score $(M=5.41, S D=.67)$ than male and female dancers of 30-39 ( $M=4.76, S D=.44), 40-49$ $(\mathrm{M}=3.29, \mathrm{SD}=.50), 50-59(\mathrm{M}=2.73, \mathrm{SD}=.34)$ and 60 plus $(\mathrm{M}=2.58, \mathrm{SD}=.55)$. c. Male and female dancers of 3039 age had higher score $(M=4.76, S D=.44)$ than male and female dancers of $40-49(M=3.29, S D=.50), 50-59$ $(M=2.73, S D=.34)$ and 60 plus $(M=2.58, S D=.55)$. $d$. Male and female dancers of 40-49 age had higher score $(M=3.29, S D=.50)$, than male and female dancers of 60 plus $(M=2.58, S D=.55)$.

3. "Identified Regulation" $f_{(5,214)}=7,03, p<.05$. More specifically: a. Male and female dancers of $15-18$ age had a higher score $(M=4.71, S D=.58)$ than male and female dancers of 40-49 $(M=4.11, S D=.77), 50-59(M=3.97$, $\mathrm{SD}=.52)$ and 60 plus $(\mathrm{M}=3.77, \mathrm{SD}=.58)$. b. Male and female dancers of 19-29 age had a higher score $(M=4.66, S D=.58)$ than male and female dancers of 60 plus age $(M=3.77, S D=.58)$.

4. "Integrated Regulation" $f_{(5,214)}=52,97, p<.05$. More specifically: a. Male and female dancers of $40-49$ age had a higher score $(\mathrm{M}=6.07, \mathrm{SD}=.64)$ than male and female dancers of 15-18 $(\mathrm{M}=3.95, \mathrm{SD}=.82), 19-29(\mathrm{M}=3.81$, $\mathrm{SD}=.64)$ and 30-39 (M=3.71, $\mathrm{SD}=.56)$. b. Male and female dancers of 50-59 age had a higher score $(M=5.84$, $\mathrm{SD}=1.05)$ than male and female dancers of $15-18(\mathrm{M}=3.95, \mathrm{SD}=.82), 19-29(\mathrm{M}=3.81, \mathrm{SD}=.64)$ and 30-39 $(\mathrm{M}=3.71, \mathrm{SD}=.56)$. $\mathrm{c}$. Male and female dancers of 60 plus age had a higher score $(\mathrm{M}=5.82, \mathrm{SD}=.44)$ than male and female dancers of 15-18 (M=3.95, SD=.82), 19-29 (M=3.81, SD=.64) and 30-39 (M=3.71, SD=.56).

Table 3. Age as a factor of differentiation

\begin{tabular}{|l|c|c|c|c|}
\hline Factor & Age & N & M & S.D. \\
\hline Intrinsic Motivation to Know & $15-18$ & 107 & 5.59 & .62 \\
& $19-29$ & 43 & 5.67 & .63 \\
& $30-39$ & 28 & 5.32 & 1.06 \\
& $40-49$ & 21 & 4.08 & .80 \\
& $50-59$ & 11 & 3.77 & .52 \\
& $60+$ & 10 & 3.45 & .16 \\
\hline Intrinsic Motivation to accomplish & $15-18$ & 107 & 5.46 & .59 \\
& $19-29$ & 43 & 5.41 & .67 \\
& $30-39$ & 28 & 4.76 & .44 \\
& $40-49$ & 21 & 3.29 & .50 \\
& $50-59$ & 11 & 2.73 & .34 \\
& $60+$ & 10 & 2.58 & .55 \\
\hline Identified Regulation & $15-18$ & 107 & 4.71 & .58 \\
& $19-29$ & 43 & 4.66 & .83 \\
& $39-39$ & 28 & 4.46 & .82 \\
& $39-49$ & 21 & 4.11 & .77 \\
& $59-59$ & 11 & 3.97 & .52 \\
& $60+$ & 10 & 3.77 & .58 \\
\hline & $15-18$ & 107 & 3.95 & .82 \\
& $19-29$ & 43 & 3.81 & .64 \\
& $30-39$ & 28 & 3.71 & .56 \\
& $40-49$ & 21 & 6.07 & .64 \\
& $50-59$ & 11 & 5.84 & 1.05 \\
& $60+$ & 10 & 5.82 & .44 \\
\hline
\end{tabular}

\section{Discussion- Conclusion}

There is a variety of researches concerning the motives of participation in dance classes. However, dancing has been treated until now as solely psychology's subject, and as an activity of leisure time and pleasure. Dancing, though, and especially the one that is presented on a stage is an activity that demands longtime exercise, preparation and the staffing of dancing groups is a competitive and tiring process. The purpose of this research is to explore the participation motives of people who take part in performance dancing, folk as well as classical and contemporary.

The results demonstrate that the participants are intrinsically motivated, as all of the three forms of intrinsic motivation, intrinsic motivation to know, intrinsic motivation toward accomplish and intrinsic motivation to experience stimulation (Vallerand, 1997), collect the highest percentage of the sample. On the contrary, lack of motivation, 
amotivation as it is called, and external regulation, collects the lowest percentage. This means that the sample of the research participates in dancing lessons because they are interested in the activity itself. Also, they participate for the pleasure they gain as they learn, as they feel satisfaction from their effort to succeed as well as for the feeling of fullness. According to the self-determination theory (Deci \& Ryan, 2000) the kind of motivation for the participation exerts a great influence on the acceptance of the hard and painful preparation, that the participation demands, in the competitive environment of theatrical dance.

The results of this research agree with the ones of the research of Thesleff (2014). According to these, students of dancing schools in Finland, who study classical and contemporary dance, are intrinsically motivated. Also, they are similar with the results of the researches conducted by Zanou, Chasandra, Goudas (2001), Doulias, Kosmidou Pavlogiannis and Patsiaouras (2005), McCleary, Weaver and Meng (2006) and Baxevanos (2008), according to which the participants are intrinsically motivated at their participation in dancing activities.

Taking into consideration age as a factor that differentiates the participation motives, we observe that younger dancers are more intrinsically motivated compared to older dancers. More specifically, male and women dancers at the first three age groups (15-18, 19-29 and 30-39) participate more frequently than their colleagues at an older age (40-49, 50-59 and 60+). This is due to the fact that, although they work hard, they get satisfaction from the whole process, through their intrinsic motivation to learn important things for the activity that interests them and through their intrinsic motivation to accomplish many achievements. The results of this research are similar with those of the research conducted by Cooper, Schuett and Phillips (2012) according to these, first year college students are more intrinsically motivated than older students, when they participate in physical activities of their college.

Having said that, for a considerable percentage of the younger age groups (15-18 and 19-29), the intrinsic motivation coexists with the extrinsic, as the factor "Identified Regulation" is more important for them than for their older colleagues. This does not oppose to the previous results, as it is natural for the percentage of these ages, to occupy themselves with this specific activity because they consider it essential, without necessarily enjoying it.

However, male and women dancers at the three older age groups (40-49, 50-59 and 60+) consider their participation in dancing activities, as an attitude that is compatible with a variety of attitudes that express human being. This is entailed naturally from the long-term occupation with dancing.

In conclusion, from all the above analysis, we can claim that dancing, even in the competitive and demanding level of its stage presentation, is an activity that its participants are intrinsically motivated and take part for the activity itself and the satisfaction that they gain, and not because they expect various economic benefits. What is more, younger dancers are at a higher level intrinsically motivated compared to older dancers, whereas sex does not seem to exert any influence that differentiates the motives of participation.

\section{References}

Bartholomew, K. J., Ntoumanis, N., \& Thøgersen-Ntoumani, C. (2009). A review of controlling motivational strategies from a selfdetermination theory perspective: implications for sports coaches. International Review of Sport \& Exercise Psychology, 2(2), 215-233.

Cooper, N., Schuett, P. A., Phillips, H. M. (2012). Examining Intrinsic Motivations in Campus Intramural Sports. Recreational Sports Journal, 36(1), 25-36.

Deci, E. L. \& Ryan, R. M. (2000). Self-determination Theory and the Facilitation of Intrinsic Motivation, Social development, and WellBeing. American Psychologist 55 (1), 68-78.

Filippou F., Serbezis V., Harahoussou Y., Kabitsis Chr., Koleta M., Varsami D., Varsami H., \& Davoras D.(2006). The folk dance as theatrical performance and the Training of Dance Teachers. Arts and Humanities in Higher Education, 5(1), 51-63.

Filippou, F., (2014). The role of the kinetic motif in determining the form and time of dance through the dance "Tis Marias". Journal of Physical Education and Sport, 14 (1), $115-119$.

Foridou, A., Tsitskari, E., Bebetsos, E., Vernadakis, N. (2012). How motives may affect young athletes' participation in team sports. JSTAR, (6), 63-78.

Lonsdale, C., Hodge, K., Rose, E. (2008). The Behavioral Regulation in Sport Questionnaire (BRSQ): Instrument Development and Initial Validity Evidence. Journal of Sport \& Exercise Psychology, (30), 323-355.

Mavridis, G., Filippou, F., Rokka, St., Bousiou, St., \& Mavridis, K. (2004). The Effect of a Health-Related Aerobic Dance Program on Elementary School Children. Human Movement Studies, 47, 337-349.

Pitsi, A., Filippou, F. (2014). Dancing and music in symbiotic groups: the example of the Vlahs-Armani of Seli Imathias-Greece. Journal of Physical Education and Sport, 14(2), 205 - 210.

Thesleff, P. (2014). Participation in dance training in Finland-A study of motives and behavior regulation. Master's Thesis in Sport and Exercise Psychology. Department of Sport Sciences - University of Jyväskylä.

Vallerand, R.J. (1997). Toward a hierarchical model of intrinsic and extrinsic motivation. Advances in Experimental Social Psychology, (29), 271-360. 